\title{
Analysis of the Influence of Pavement Irregularities on the Lifespan of a Vehicle's Drive-Wheel Half Shaft
}

\author{
Sreten Simović1,* - Vladimir Popović2 - Milanko Damjanović1 \\ 1 University of Montenegro, Faculty of Mechanical Engineering, Montenegro \\ 2 University of Belgrade, Faculty of Mechanical Engineering, Serbia
}

\begin{abstract}
As a complex technical system, a vehicle requires a full analysis of its dynamic behaviour. A vehicle is the research subject requiring a detailed analysis of all separate systems both individually and in mutual interaction. One of the technical aspects of vehicle analysis is the lifespan of each element. This paper presents an analysis of the impact of the characteristics of pavement irregularities on the lifespan of a half shaft. In this paper, a mathematical model and a computer simulation of vehicle half-shaft loads have been set up. The importance of this approach is reflected in the use of state-of-the-art computational methods of analysis. The obtained results enable the drawing of clear conclusions about the effects of pavement properties on the lifespan of a vehicle half shaft.

Keywords: vehicle, pavement, half shaft, load, lifespan

Highlights

- The influence of pavement irregularities on a vehicle drive-wheel half shaft is analysed.

- A mathematical model of vehicle half-shaft loads has been set up and the influence on lifespan is analysed.

- Simulation results of dynamic behaviour were tested and verified through experiments.

- $\quad$ Results show that the presented analytical model can be used for the analysis of a vehicle's behaviour when wheel passing over irregularities.

- $\quad$ The pavement characteristics significantly affect a vehicle half shaft's stress and lifespan.
\end{abstract}

\section{INTRODUCTION}

During their service life, vehicles are faced with a wide spectrum of vibrations. These vibrations are primarily triggered by surface irregularities and internal sources, where the forces and moments generated by the contact between a surface and wheels have the greatest influence [1] to [3]. In addition to the demands of efficacy, emissions, and safety, vehicles are simultaneously faced with many demands that are reflected in the achievement of comfort, driveability, low wear, availability and long-term functionality [4].

Besides the complexity of the vehicle structure, dynamic behaviour and interaction between vehicle systems and the environment, most analyses consider only individual parts of vehicle systems [5]. In that sense, the vehicle drivetrain system is frequently the subject of research, which is to be expected given its importance in its interactions with other vehicle systems. Thus, a great deal of reference literature sources shows the analysis of a vehicle drivetrain system with road irregularities as the input in the system or in engine and vehicle models to emulate vehicle drivetrain loads [6] to [8]. There is a noticeable lack of analyses and conclusions on the influences of the vehicle systems' characteristics and pavement characteristics on the lifespan of the vehicle drivetrain system elements. Indeed, the complexity of a vehicle structure and the behaviour of the deformable wheel when it passes over an irregularity is a huge problem in this analysis, because there is no complete and satisfactory theory to explain that process [9].

Regarding the process of force and torque generation, the characteristics of a tyre are also very important. A wheel has a function to protect a vehicle against surface irregularities, which requires a deep analysis to provide the characteristics of a vehicle use and the need for the accomplishment of a long lifespan. Such an analysis must provide a prediction of behaviour according to drive inputs and influences of the surface irregularities and surface properties. The theoretical research frequently argues that the dynamic vehicle behaviour also depends on the characteristics of change of a vertical force that, among other factors, depends on the characteristics of a suspension system [10]. The previously stated indicates the conclusion that the analysis of vehicle systems' dynamic behaviour must include the influence of a wheel as a deformable element, the determination of reliance between the displacement of the unsprung and sprung masses and analysis of the oscillatory system consisting of a wheel, drive axle, suspension, and a vehicle frame [6]. Papers [11] and [12] present an analysis of the various vehicle suspension systems.

There are many tyre models, e.g. Magic Formula, Fiala, Delft Tyre 97, etc. [1]. However, the fact is 
that when a model is simpler, it will possibly be less accurate, while a more complex model will be less suitable for the vehicle motion simulations. A detailed analysis of the wheel dynamics is usually done with the data obtained from the performed experimental investigations where the wheel-pavement contact is analysed and the conclusions about the particular characteristics were drawn, for example that the main parameters of the tyre influencing the generated force are the vertical and the radial stiffness of a tyre, where the pneumatic damping characteristic may be neglected, [13] to [15].

The need to perform an analysis of a vehicle systems element lifespans is also clearly indicated. The importance of this analysis is proven by fact that a vehicle durability depends on design geometry, material properties, and load, with road roughness as an important parameter influencing the vehicle load. The analysis of the lifespan of vehicle drivetrain system elements in relation to the diversity of pavement characteristics shows that the design of vehicle systems should be adjusted to the vehicle exploitation condition, [10].

Thus, different approaches in the process of solving certain problems in a lifespan analysis are used [16]. In the analysis of lifespan, the real conditions are usually replaced by the values of the estimated forces and stresses acting on the vehicle system elements [17] and [18]. The fatigue and reliability tests may be performed in terms of analysing different roads, analysing interacting influences of some mass and geometrical parameters of the vehicles or analysis of the relative fatigue damage of the drivetrain systems for specific roads [19] to [21].

\section{DETERMINATION OF LOADS AND ESTIMATION OF LIFESPAN}

The analyses of vehicle elements' lifespan are usually conducted in terms of a service life and an analysis of the load of some vehicle elements. In this regard, an analysis investigating the interactive influence of the vehicle elements and the necessity of their analysing as a unique dynamic system is very important [22]. Due to the complexity of the analysed system, any analysis of the lifespan of the vehicle drivetrain requires a meticulous approach. Therefore, in the process of the development of a vehicle the measurements and simulation data must be combined; for instance, in that process the vehicle performance may be predicted fairly exactly, but a fatigue life estimation, as a result of a more complex analysis, permits only relative statements, and they are always supported by tests [23]. In that sense, [24] presents a system for the continual tracking of working conditions and the estimation of a remaining lifespan of automotive transmission gear wheels, while the model of a drive system and the damage of a gearwheel are presented in [25]. Within the analysis of a lifespan of a driving axle, the time of a vehicle use in some gear ratios and types of road must be taken into account [26] and [27].

Since vehicle motion is characterised by a constant change of wheel-road interactions, i.e. generated forces and stresses, thence determination of a variability, values and laws on the distribution of working and permissible stresses in relation to road conditions represent a major problem in the analysis [28]. The analytic determination of the loads requires a mathematic description of a dynamic behaviour of a drivetrain and the processing of the stresses in elements. When the stress recording is processed, its discretisation is carried out in a manner in which the real load is replaced by a load equivalent to the original load.

In real exploitation conditions, the stress changes are multi-cyclic with a changeable amplitude and a mean stress. The elements' strength in such a change of loads is a working strength that can be determined by experimental testing, using the basic strength or in a theoretically-experimental way using the hypothesis about the fatigue accumulation. Working strength is most accurately obtained by direct experimental testing, but this is mostly not acceptable because comprehensive, long-term, and expensive research is necessary. The hypotheses of the material damage accumulation enabling the calculation estimation of an element's lifespan is widely used in the determination of working strength.

The first hypotheses about a material damage accumulation were developed by Palmgrin, and Miner expanded them [28]. Palmgrin-Miner's damage hypothesis represents a basis for other hypotheses about the damage accumulation, on the basis of which the total damage is calculated as a sum of individual items of damage due to stresses and assume that a fatigue crack occurs when the interaction function, ar, is equal to 1 .

The value of interaction function is:

$$
a_{r}=\sum_{i=1}^{j} \frac{n_{i}}{N_{i}} ; \text { for } \tau_{i} \geq \tau_{D}
$$

where $n_{i}$ is the number of cycles of the stress of the $i^{\text {th }}$ level, $\tau_{i}$, for the entire lifespan, $N_{i}$ is the number of changes of stresses on the $i^{\text {th }}$ level that an element can endure, $j$ is the total number of the levels of stress, $\tau_{D}$ is the fatigue limit strength, Fig. 1. 


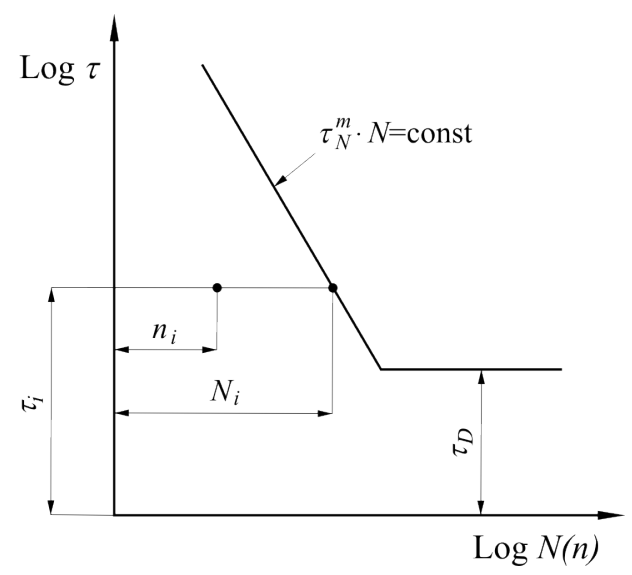

Fig. 1. Wöhler's diagram

In the total number of cycles, the changes of stress of all weights to the failure of an element $N_{R}$ the participation of each stress $\tau_{i}$ is comparable to the participation of this same stress in a unit spectrum $n_{b i} / n_{b}$ namely:

$$
n_{i}=N_{R} \cdot \frac{n_{b i}}{n_{b}}
$$

where $N_{R}$ is the total number of changes of working stresses of all levels that an element can endure to a fracture, $n_{b i}$ is the number of changes of stresses of the $i^{\text {th }}$ level in a unit spectrum, $n_{b}$ is the total number of changes of stresses of all levels in a unit spectrum.

From the equation of a curve of a dynamic endurance, Wöhler's curve, we obtain:

$$
\begin{gathered}
\tau_{i}^{m} \cdot N_{i}=\tau_{D}^{m} \cdot N_{D}=\tau_{1}^{m} \cdot N_{1}, \\
N_{i}=N_{D} \cdot\left(\frac{\tau_{D}}{\tau_{i}}\right)^{m}=N_{1} \cdot\left(\frac{\tau_{1}}{\tau_{i}}\right)^{m},
\end{gathered}
$$

where $N_{D}$ is a base cycle number, $N_{1}$ number of changes of maximum working stress, $\tau_{1}$ maximum working stress, $\tau_{i}$ working stress on $i^{\text {th }}$ level.

Using Palmgrin-Miner's damage hypothesis, the component's service life in load cycles, $N_{R}$, is calculated according to:

$$
N_{R}=\frac{N_{D}}{\sum_{i=1}^{j} \frac{n_{b i}}{n_{b}} \cdot\left(\frac{\tau_{i}}{\tau_{D}}\right)^{m}} \text {; for } \tau_{i}>\tau_{D} .
$$

For the purpose of the improvement of PalmgrinMiner's damage hypothesis, several corrected linear hypotheses were developed and the most important are Corten-Dolan's, Haibach's and Sorensen-Kogaev's hypotheses. Corten-Dolan's damage hypothesis adds the elementary damage along the modified fatigue line for all sorts of stresses, and, according to Haibach's damage hypothesis, the influence of stresses with values lower than the fatigue limit strength is assumed according to a fictitious line on Wöhler's diagram without the removal of smaller stresses. Both hypotheses assume that a fatigue crack occurs when the interaction function, $a_{r}$, is equal to 1, [28].

The comparison of previously mentioned hypotheses is presented on Wöhler's diagram given in Fig. 2.

Sorensen-Kogaev's damage hypothesis represents a modification of Palmgrin-Miner's hypothesis where a fatigue crack occurs when a sum of relative damages reaches the value of the calculated interaction function. The impact on the dynamic strength of stresses with values lower than the fatigue limit strength is assumed by the coefficients of a stress spectrum shape by which the calculation accuracy is improved in relation to Palmgrin-Miner's hypothesis. With the use of Sorensen-Kogaev's damage hypothesis, the calculation of the influence of a stresses with values lower than the fatigue limit strength on a working strength of elements is carried out for each specific case.

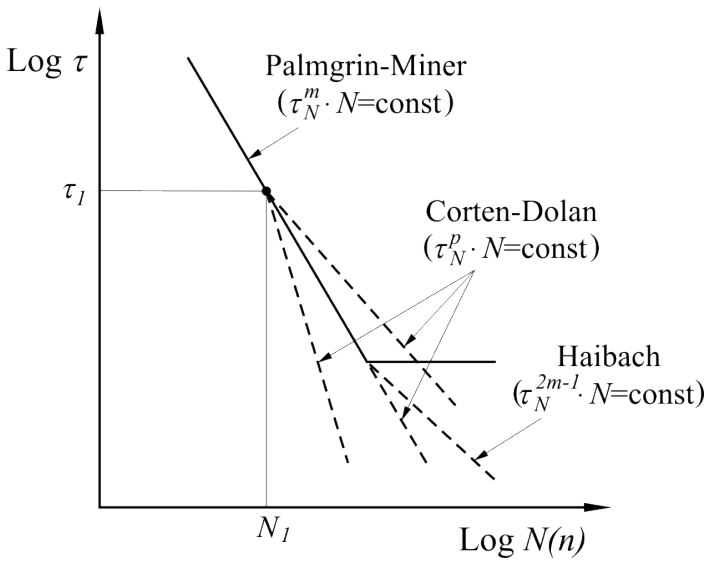

Fig. 2. The comparison of hypotheses

The value of interaction function for SorensenKogaev's damage hypothesis is calculated using Eq. (6):

$$
a_{r}=\frac{\tau_{1} \cdot \sum_{k \cdot \tau_{D}}^{\tau_{1}} \frac{\tau_{i}}{\tau_{1}} \cdot \frac{n_{b i}}{n_{b}}-k \cdot \tau_{D}}{\tau_{1}-k \cdot \tau_{D}},
$$

where $k$ is a constant determining the bottom limit of stresses causing the damage of the material $(k=0.5)$.

Using Sorensen-Kogaev's damage hypothesis, the component's service life in load cycles, $N_{R}$, is calculated according to: 


$$
N_{R}=\frac{a_{r} \cdot N_{D}}{\sum_{i=1}^{j} \frac{n_{b i}}{n_{b}} \cdot\left(\frac{\tau_{i}}{\tau_{D}}\right)^{m}} ; \text { for } \tau_{i}>\tau_{D}
$$

In order to compare the results of use of the mentioned hypothesis, some papers show results in which a reliability evaluation in use of PalmgrinMiner's and Corten-Dolan's hypothesis leads to higher values of a driving shaft reliability than reliability evaluation using Haibach's and Sorensen-Kogaev's hypothesis, yielding the result for a lifespan that is closer to a real life cycle. The comparison of the results of a reliability evaluation in the use of Haibach's and Sorensen-Kogaev's damage hypothesis shows higher values of driving shaft reliability for road conditions with a higher share of roads being macadam and roads with a lower quality of a pavement surface in use of Haibach's damage hypothesis, [29].

\section{ANALYSIS OF THE INFLUENCE OF PAVEMENT IRREGULARITIES}

In order to conduct the analysis, relatively simple mathematical models of the drivetrain and suspension systems and the pavement characteristics were created, using the schematic for vehicle systems shown in Fig. 3.

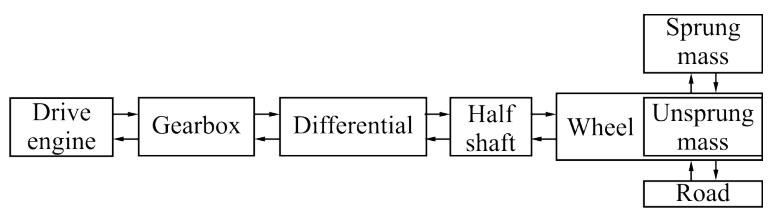

Fig. 3. Vehicle systems

The simulation of the dynamic behaviour of the vehicle system presented by equivalent mass, momentum, stiffness, and damping was performed through the linearized state-space equations of the quarter car model, as follows:

a. the drivetrain:

- engine:

$$
\begin{gathered}
\Delta M_{e}=\frac{\partial M_{e}}{\partial \omega_{e}} \cdot \Delta \omega_{e}+\frac{\partial M_{e}}{\partial h} \cdot \Delta h \\
J_{e} \cdot \Delta \ddot{\varphi}_{e}=\frac{\partial M_{e}}{\partial \omega_{e}} \cdot \Delta \omega_{e}-\left[k_{e} \cdot\left(\Delta \varphi_{e}-\Delta \varphi_{\text {out }, e}\right)+\right. \\
\left.+c_{e} \cdot\left(\Delta \dot{\varphi}_{e}-\Delta \dot{\varphi}_{\text {out }, e}\right)\right],
\end{gathered}
$$

where $k_{e}$ and $c_{e}$ are the equivalent stiffness and damping of the engine, $J_{e}$ the momentum of the engine, $\varphi_{e}$ the angle of rotation of the crankshaft, $\varphi_{\text {out }, e}$ the angle of rotation of the crankshaft, $h$ the position of the accelerator and $M_{e}$ the output torque,

- gearbox:

$$
\begin{gathered}
\left(J_{1}+\frac{J_{2}}{i_{g}^{2}}\right) \cdot \ddot{\varphi}_{g}=M_{p, g}-\frac{1}{i_{g}} . \\
\cdot\left[k_{g} \cdot\left(\frac{\varphi_{g}}{i_{g}}-\varphi_{\text {out }, g}\right)+c_{g} \cdot\left(\frac{\dot{\varphi}_{g}}{i_{g}}-\dot{\varphi}_{\text {out }, g}\right)\right],
\end{gathered}
$$

where $M_{p, g}$ is gearbox input torque, $k_{g}$ and $c_{g}$ the equivalent stiffness and damping of the gearbox, $J_{1}$, $J_{2}$ the momentums of the gearbox presented with two masses, $\varphi_{g}$ the angle of rotation of the input gearbox shaft, $\varphi_{\text {out }, g}$ the rotation angle of the output transmission shaft and $i_{g}$ the transmission ratio,

- half shaft:

$$
\begin{aligned}
J_{h s} \cdot \ddot{\varphi}_{h s} & =M_{p, h s}-\left[k_{h s} \cdot\left(\varphi_{h s}-\varphi_{\text {out }, h s}\right)+\right. \\
& \left.+c_{h s} \cdot\left(\dot{\varphi}_{h s}-\dot{\varphi}_{\text {out }, h s}\right)\right],
\end{aligned}
$$

where $M_{p, h s}$ are the half-shaft input torque, $k_{h s}$ and $c_{h s}$ are the equivalent stiffness and damping, $J_{h s}$ the momentum of the half shaft, $\varphi_{h s}$ the rotation angle of the half shaft and $\varphi_{\text {out,hs }}$ the rotation angle of the output,

- differential:

$$
\begin{aligned}
& {\left[J_{1}+\frac{J_{2}}{i_{0}^{2}}+\frac{J_{3}}{\left(i_{p(l)} \cdot i_{0}\right)^{2}}+\frac{J_{4}}{\left(i_{z(d)} \cdot i_{0}\right)^{2}}\right] \cdot \ddot{\varphi}_{d}=} \\
& =M_{p, d}-\left[M_{r e s, f(l)}+M_{r e s, r(r)}\right] \text {. } \\
& M_{r e s, f(l)}=\frac{1}{i_{0} \cdot i_{f(l)}} \cdot\left[k_{\text {out }, f(l)} \cdot\left(\frac{\varphi_{d}}{i_{0} \cdot i_{f(l)}}-\varphi_{\text {out }, f(l)}\right)+\right. \\
& \left.+c_{\text {out }, f(l)} \cdot\left(\frac{\dot{\varphi}_{d}}{i_{0} \cdot i_{f(l)}}-\dot{\varphi}_{\text {out }, f(l)}\right)\right] \\
& M_{r e s, r(r)}=\frac{1}{i_{0} \cdot i_{r(r)}} \cdot\left[k_{\text {out }, r(r)} \cdot\left(\frac{\varphi_{d}}{i_{0} \cdot i_{r(r)}}-\varphi_{\text {out }, r(r)}\right)+\right. \\
& \left.+c_{\text {out }, r(r)} \cdot\left(\frac{\dot{\varphi}_{d}}{i_{0} \cdot i_{r r(r)}}-\dot{\varphi}_{\text {out }, r(r)}\right)\right],
\end{aligned}
$$


where $M_{p, d}$ are the differential input torque, $i_{0, f(1), r(r)}$ the gear ratios in the differential, $k_{\text {out }, f(1), r(r)}$ and $c_{\text {out } f(1), r(r)}$ the equivalent stiffness and damping of the differential shaft, $J_{1}, J_{2}, J_{3}, J_{4}$ the momentums of the differential, $\varphi_{d}$ the rotation angle of the differential input shaft, $\varphi_{\text {out }, f(1), r(r)}$ the rotation angle of the differential output shafts and $M_{r e s, f(1), r(r)}$ the torque of resistance of the differential output shafts,

- drive-wheel, Figs. 4 and 5:

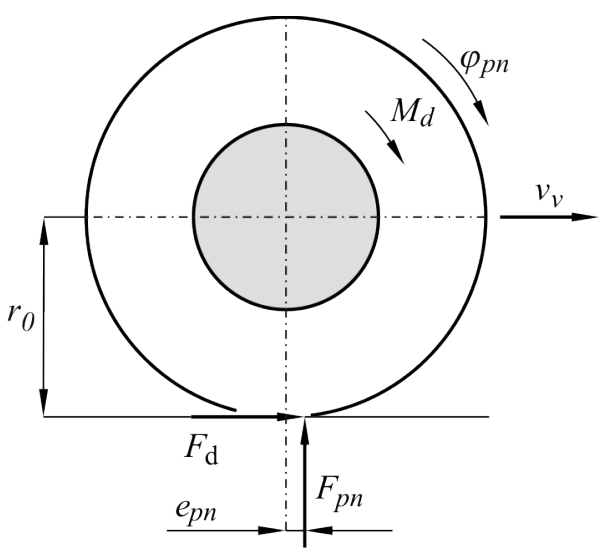

Fig. 4. Load of vehicle wheel

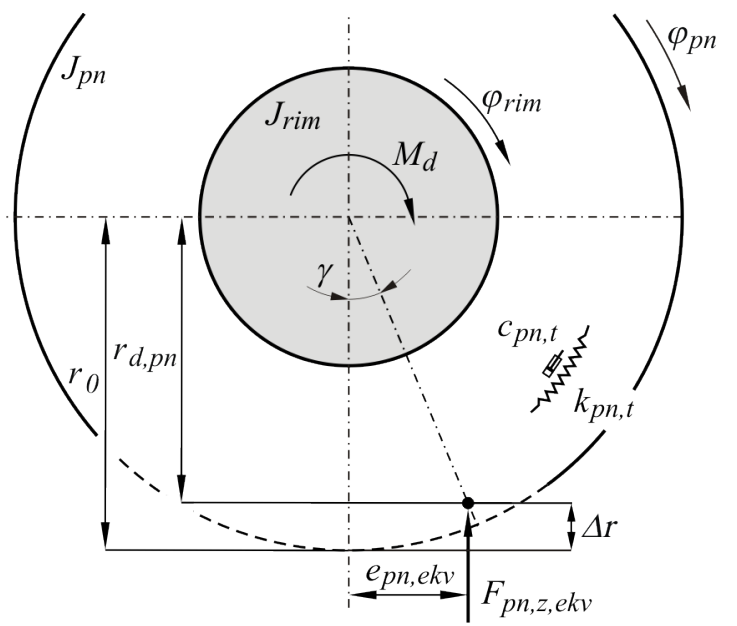

Fig. 5. Wheel scheme

$$
\begin{aligned}
J_{r i m} \ddot{\varphi}_{r i m}= & M_{d}-\left[k_{p n, t} \cdot\left(\varphi_{r i m}-\varphi_{p n}\right)+\right. \\
& \left.+c_{p n, t} \cdot\left(\dot{\varphi}_{r i m}-\dot{\varphi}_{p n}\right)\right], \\
J_{p n} \ddot{\varphi}_{p n}= & {\left[k_{p n, t} \cdot\left(\varphi_{r i m}-\varphi_{p n}\right)+\right.} \\
& \left.+c_{p n, t} \cdot\left(\dot{\varphi}_{r i m}-\dot{\varphi}_{p n}\right)\right]-M_{r e s}, \\
M_{r e s}= & F_{p n, z, e k v} \cdot e_{p n, e k v},
\end{aligned}
$$

$$
\begin{gathered}
e_{p n, e k v, u l}=r_{0} \cdot \frac{z_{p, t, p e g}}{s}, \\
\ddot{e}_{p n, e k v}+A \cdot B \cdot e_{p n, e k v}+A^{2} \cdot e_{p n, e k v}=A^{2} \cdot C \cdot e_{p n, e k v, u l}, \\
e_{p n, e k v}=e_{p n, e k v, 0}\left(\text { for } z_{p, t, p e g}=0\right),
\end{gathered}
$$

where $M_{d}$ is the wheel input torque, $k_{p n, t}$ and $c_{p n, t}$ are the tangential stiffness and damping of the tyre, $J_{\text {rim }}$, $J_{p n}$ the momentums of the wheel rim and tyre, $\varphi_{\text {rim }}, \varphi_{p n}$ the rotation angle of the wheel rim and tyre, $M_{\text {res }}$ the resistance torque, $F_{p n, z, e k v}$ the equivalent vertical force on the tyre, $e_{p n, e k v}$ the equivalent arm of the vertical force, $r_{0}$ the outer radius of the tyre, $s$ the distance travelled in $0.01 \mathrm{~s}$ and $z_{p, t, p e g}$ the effective value of the irregularity height, $\mathrm{A}, \mathrm{B}, \mathrm{C}$ constants.

b. suspension system, Fig. 6 :

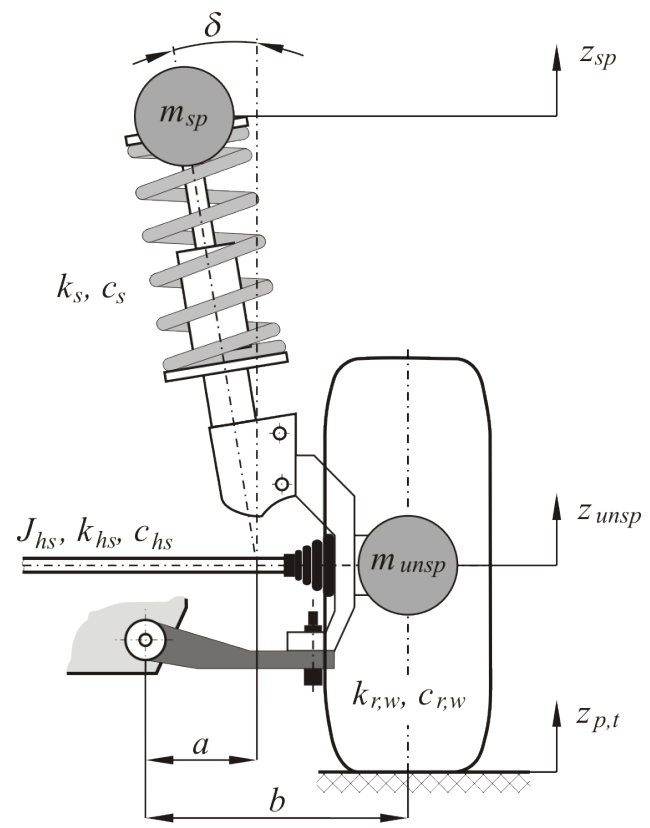

Fig. 6. Suspension system

$$
\begin{gathered}
m_{s p} \cdot \ddot{z}_{s p}=k_{s} \cdot\left(z_{\text {unsp }}-z_{s p}\right)+c_{s} \cdot\left(\dot{z}_{\text {unsp }}-\dot{z}_{s p}\right), \\
m_{\text {unsp }} \cdot \ddot{z}_{u n s p}=\left[k_{r, w} \cdot\left(z_{p, t}-z_{\text {unsp }}\right)+c_{r, w} \cdot\left(\dot{z}_{p, t}-\dot{z}_{\text {unsp }}\right)\right]- \\
-\left[k_{s} \cdot\left(z_{\text {unsp }}-z_{s p}\right)+c_{s} \cdot\left(\dot{z}_{\text {unsp }}-\dot{z}_{s p}\right)\right] \cdot \cos \delta \cdot \frac{a}{b}, \\
F_{p n, z, e k v}=k_{r, w} \cdot\left[z_{p, t}-z_{\text {unsp }}\right]+c_{r, w} \cdot\left[\dot{z}_{p, t}-\dot{z}_{\text {unsp }}\right], \\
F_{p n, z}=k_{r, w} \cdot\left[z_{p, t, p e g}-z_{\text {unsp }}\right]+c_{r, w} \cdot\left[\dot{z}_{p, t, p e g}-\dot{z}_{\text {unsp }}\right],
\end{gathered}
$$


where $a$ and $b$ are the distances in the vehicle suspension system, $\delta$ the angle of inclination of the suspension system, $k_{s}$ and $c_{s}$ the equivalent stiffness and damping of the suspension system, $m_{s p}$ and $m_{\text {unsp }}$ the sprung and unsprung masses, $k_{r, w}$ and $c_{r, w}$ the radial tyre stiffness and damping, $z_{s p}$ and $z_{\text {unsp }}$ the position of the sprung and unsprung masses, $F_{p n, z}$ and $F_{p n, z, e k v}$ the vertical and equivalent vertical force on the wheel and $z_{p, t}$ and $z_{p t, p e g}$ the road irregularity and equivalent irregularity height.

\section{c. road irregularities:}

As the tyre is a deformable element of the system simultaneously in contact with a number of irregularities, it is necessary to take into account the impact of the deformable tyre that is reflected in smoothing irregularities. This characteristic of a tyre is given in the form of the transfer function of the dynamic chain in which the input value is the ordinate of the road surface micro-profile and the output obtained is its mean height at the length of the contact zone between the tyre and the road surface, [6] and [30]:

$$
W_{p e g}(j \omega)=\frac{k_{p l}^{2}}{(j \omega)^{2}+j \omega \cdot k_{p l} \cdot \sqrt{2}+k_{p l}^{2}},
$$

where $k_{p l}$ is a coefficient that is calculated by the expression:

$$
k_{p l}=(0.9 \div 1.3) \cdot \frac{v}{l_{t}}
$$

where $l_{t}$ is the length of contact between the road surface and tyre, and $v$ is the vehicle speed.

The parameter $l_{t}$ is obtained by using the expression:

$$
l_{t}=2 \cdot \sqrt{0.1 \cdot H_{t} \cdot\left(D_{t}-0.1 \cdot H_{t}\right)}
$$

where $D_{t}$ and $H_{t}$ are the outer radius and the height of the tyre profile.

The spectral density of the process smoothed by the tyre $S_{p e g}$ is obtained by the transfer function:

$$
\begin{aligned}
& S_{p e g}(\omega)=W_{p e g}(j \omega) \cdot W_{p e g}(-j \omega) \cdot S_{h}(\omega), \\
& S_{p e g}(\omega)=\frac{k_{p l}^{2}}{\left(k_{p l}^{2}-\omega^{2}\right)^{2}+2 \cdot k_{p l}^{2} \cdot \omega^{2}} \cdot S_{h}(\omega),
\end{aligned}
$$

where $S_{h}$ is the spectral density of the micro profile.

Based on the transfer function shown above, the following differential equation is obtained, enabling the calculation of the equivalent height of an irregularity. This is relevant to the calculation of the behaviour of the system under the influence of the irregularities:

$$
\ddot{z}_{p, t, p e g}+\dot{z}_{p, t, p e g} \cdot k_{p l} \cdot \sqrt{2}+z_{p, t, p e g} \cdot k_{p l}^{2}=k_{p l}^{2} \cdot z_{p, t} \text {, }
$$

where $z_{p, t}$ is the accidental height of the irregularity.

\section{VALIDATION OF MATHEMATICAL MODEL}

The validation of a mathematical model requires the comparison of the obtained results with the data about the real system behaviour. In that sense, before the execution of an analysis of a lifespan, a validation of a model via the comparison of results of computer simulation with the results of the experimental testing should be carried out [4]. Regarding the necessary steps in the analysis, a previously performed individual analysis of the steps for passenger cars with front drive shafts and McPherson struts was used [31]. The experiment was performed on a real vehicle, where the engine drive torque and the number of revolutions were maintained at an approximately constant value. The vehicle was moving in a straight line over an ideally flat concrete surface at a constant speed of approximately $20 \mathrm{~km} / \mathrm{h}$ and over a triangular irregularity with a height of $55 \mathrm{~mm}$ and length of 190 $\mathrm{mm}$.

The validation was done via the comparison of data obtained from the simulations of a one-quarter car model, performed under the conditions in which the experiment was conducted. The comparison was performed for a change of a spring-damper length, $z_{u n s p}-z_{s p}$, and for the change of drive torque on the half shaft, $M_{d}$. The parameters used for a computer simulation are shown in Table 1 [31].

The results of the validation are shown in Figs. 7 and 8 which show the results of experimental testing and computer simulations.

The diagrams presented in Figs. 7 and 8 clearly indicate that the simulation and the experimentally obtained results regarding the suspension and drivetrain system show a very good compliance, by which it can be concluded that the presented analytical model has an advantage and can be used for the analysis of vehicle behaviour when passing over irregularities.

\section{SIMULATION OF DYNAMIC BEHAVIOUR}

The computer simulation of the dynamic behaviour of the drivetrain and suspension systems under the influence of disturbances caused by pavement 
Table 1. Simulation parameters

\begin{tabular}{|c|c|c|c|}
\hline System & Symbol & Value & Unit \\
\hline \multirow{5}{*}{ Drive engine } & $M_{0}$ & 150 & $\mathrm{Nm}$ \\
\hline & $\partial M_{e} / \partial \omega_{e}$ & -0.5 & $\mathrm{Nms}$ \\
\hline & $J_{e}$ & 0.15 & $\mathrm{kgm}^{2}$ \\
\hline & $k_{e}$ & 3 & $\mathrm{kNm} / \mathrm{rad}$ \\
\hline & $c_{e}$ & 0.1 & $\mathrm{Nms} / \mathrm{rad}$ \\
\hline \multirow{4}{*}{ Gearbox } & $J_{1}, J_{2}$ & 0.02 & $\mathrm{kgm}^{2}$ \\
\hline & $i_{g}$ & 3.6 & - \\
\hline & $k_{g}$ & 3 & $\mathrm{kNm} / \mathrm{rad}$ \\
\hline & $c_{g}$ & 0.1 & $\mathrm{Nms} / \mathrm{rad}$ \\
\hline \multirow{4}{*}{ Differential } & $J_{1}, J_{2}, J_{3}, J_{4}$ & 0.02 & $\mathrm{kgm}^{2}$ \\
\hline & $i_{0}$ & 3.58 & - \\
\hline & $k_{\text {out }, f(1)}$ & 3.5 & $\mathrm{kNm} / \mathrm{rad}$ \\
\hline & $c_{\text {out } f(1)}$ & 0.1 & $\mathrm{Nms} / \mathrm{rad}$ \\
\hline \multirow{3}{*}{ Half shaft } & $J_{h s}$ & 0.0003 & $\mathrm{kgm}^{2}$ \\
\hline & $k_{h s}$ & 5 & $\mathrm{kNm} / \mathrm{rad}$ \\
\hline & $c_{h s}$ & 0.1 & $\mathrm{Nms} / \mathrm{rad}$ \\
\hline \multirow{11}{*}{ Drive-wheel } & $J_{\text {rim }}$ & 14 & $\mathrm{kgm}^{2}$ \\
\hline & $k_{r, w}$ & 220 & $\mathrm{kN} / \mathrm{m}$ \\
\hline & $c_{r, w}$ & - & - \\
\hline & $k_{p n, t}$ & 4.5 & $\mathrm{kNm} / \mathrm{rad}$ \\
\hline & $c_{p n, t}$ & 2 & $\mathrm{Nms} / \mathrm{rad}$ \\
\hline & $J_{p h}$ & 0.3 & $\mathrm{kgm}^{2}$ \\
\hline & $r_{0}$ & 0.293 & $\mathrm{~m}$ \\
\hline & $e_{0}$ & 0.04 & $\mathrm{~m}$ \\
\hline & A & 130 & $1 / \mathrm{s}$ \\
\hline & B & 1.5 & - \\
\hline & $\mathrm{C}$ & 3 & - \\
\hline \multirow{8}{*}{$\begin{array}{l}\text { Suspension } \\
\text { system }\end{array}$} & $m_{s p}$ & 280 & $\mathrm{~kg}$ \\
\hline & $k_{s}$ & 19 & $\mathrm{kN} / \mathrm{m}$ \\
\hline & $c_{S}$ & 2 & $\mathrm{kNs} / \mathrm{m}$ \\
\hline & $m_{\text {unsp }}$ & 45 & $\mathrm{~kg}$ \\
\hline & $\delta$ & 7.6 & $\circ$ \\
\hline & $a$ & 0.27 & $\mathrm{~m}$ \\
\hline & $b$ & 0.32 & $\mathrm{~m}$ \\
\hline & $k_{p l}$ & 1.1 & $1 / \mathrm{s}$ \\
\hline
\end{tabular}

Table 2. Pavement characteristics (coefficient of approximation of the auto-correlative function)

\begin{tabular}{lcccccc}
\hline $\begin{array}{c}\text { Road surface } \\
\text { pavement }\end{array}$ & $\begin{array}{c}D_{k} \\
{\left[\mathrm{~cm}^{2}\right]}\end{array}$ & $A_{1}$ & $A_{2}$ & $\alpha_{1}$ & $\alpha_{2}$ & $\beta$ \\
\hline 1. Asphalt (good) & 0.664 & 1 & 0 & 0.13 & 0 & 1.05 \\
\hline 2. Asphalt (used) & 1.21 & 0.15 & 0.85 & 0.05 & 0.2 & 0.6 \\
\hline 3. Gravel & 6.3 & 0.047 & 0.9553 & 0.049 & 0.213 & 1.367 \\
\hline 4. Stubble (field) & 10.63 & 0.1 & 0.9 & 0.2 & 0.7 & 1.57 \\
\hline
\end{tabular}

irregularities, for the purpose of an analysis of a lifespan of a vehicle half shaft, was done using the previously presented analytical model. The pavement characteristics are presented as a stationary ergodic

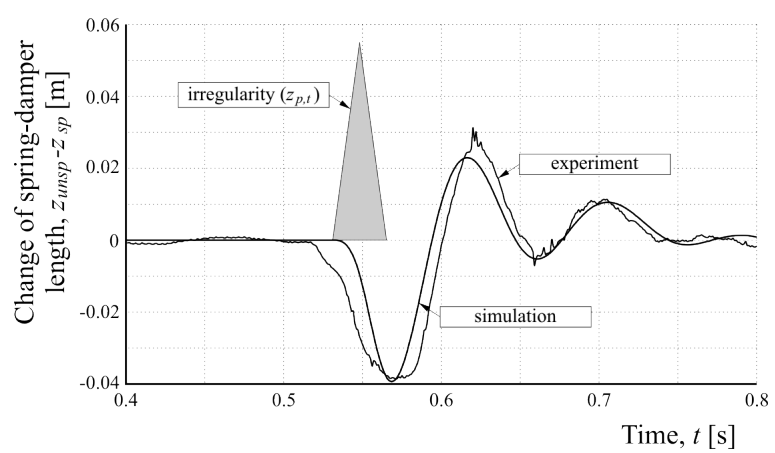

Fig. 7. Change of front axle spring-damper length

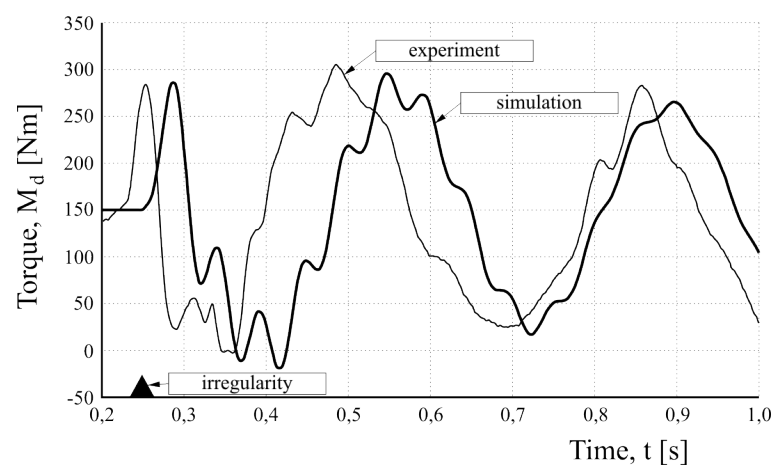

Fig. 8. Change in the drive torque on the half shaft

random process with an auto-correlative function, $R_{k}(t)$, defined using the expression:

$$
R_{k}(t)=D_{k} \cdot\left[A_{1 k} \cdot e^{-\alpha_{1 k} \cdot t} \cdot \cos \left(\beta_{k} \cdot t\right)+A_{2 k} \cdot e^{-\alpha_{2 k} \cdot t}\right] .
$$

Therefore, simulations of the dynamic behaviour of the system when crossing four types of pavement were made, and pavement characteristics are given in Table 2 [30].

The dynamic behaviour was simulated in MATLAB Simulink, in a time corresponding to a vehicle motion for 30 seconds, with a step of random excitation of the pavement irregularity of 0.01 seconds. Reflecting that, Figs. 9 and 10 show the best and worst pavement characteristics in terms of surface irregularities (pavements 1 and 4 respectively), and Figs. 11 to 14 show the change in a torque on the half shaft when a drive-wheel crosses over the four characteristic pavements.

\section{ANALYSIS}

Since the measurement readings of a random change in the load cannot be used directly in the calculation of the lifespan of a vehicle half shaft, the readings were converted into a suitable form. To achieve this, 


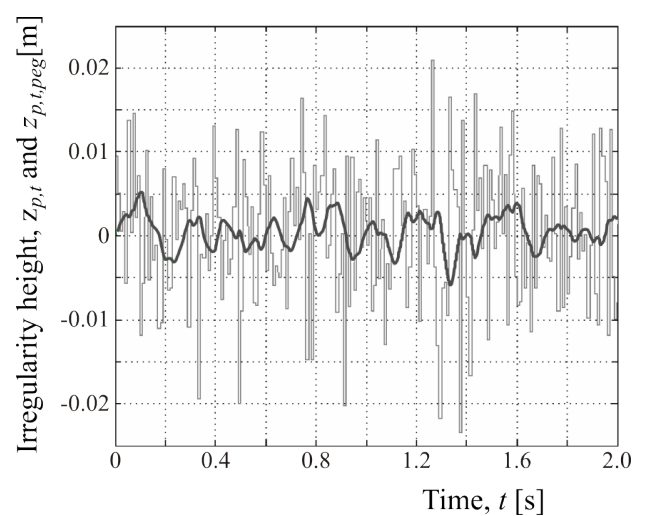

Fig. 9. Changes in the random pavement height profile under the drive-wheel when passing over Pavement 1; (gray thiner line - random input, gray thicker line - smoothed pavement height characteristic)

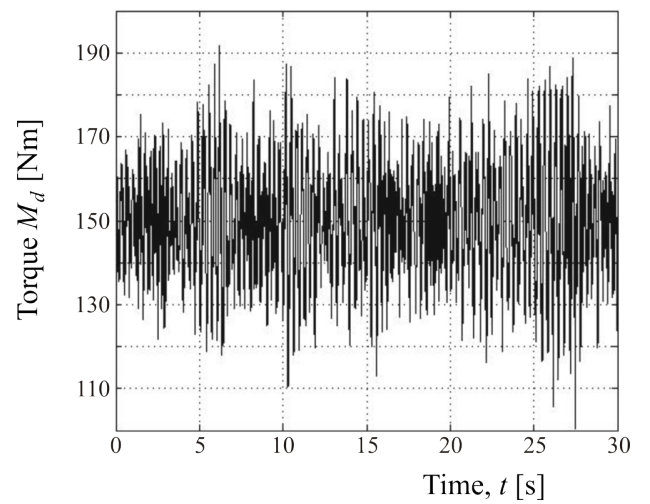

Fig. 11. Changes in torque on the half shaft when drive-wheel passing over Pavement 1

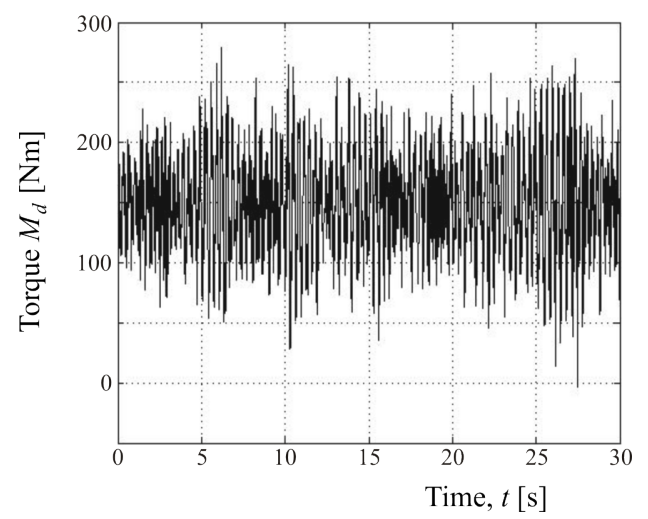

Fig. 13. Changes in torque on the half shaft when drive-wheel passing over Pavement 3

the rain flow method was used (pagoda roof method), [32].

After the processing of the diagrams of the torque change on the half shaft when a drive-wheel passes over a random pavement irregularity (shown in Figs. 11 to 14) which are divided into twenty classes of amplitude range, Figs. 15 to 22 show the histograms of

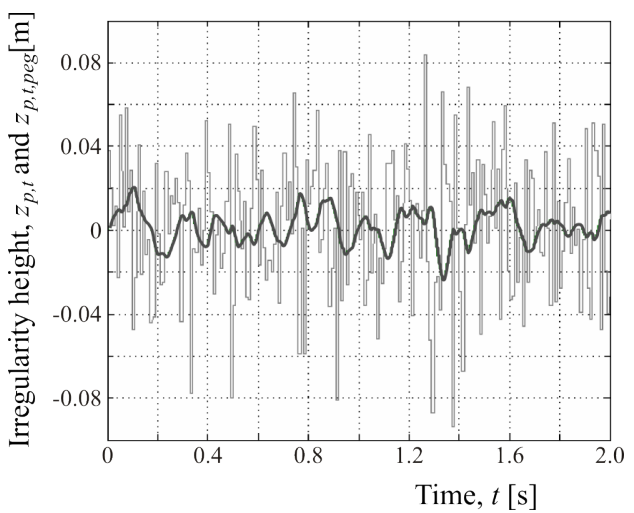

Fig. 10. Changes in the random pavement height profile under the drive-wheel when passing over Pavement 4 (gray thiner line - random input, gray thicker line - smoothed pavement height characteristic)

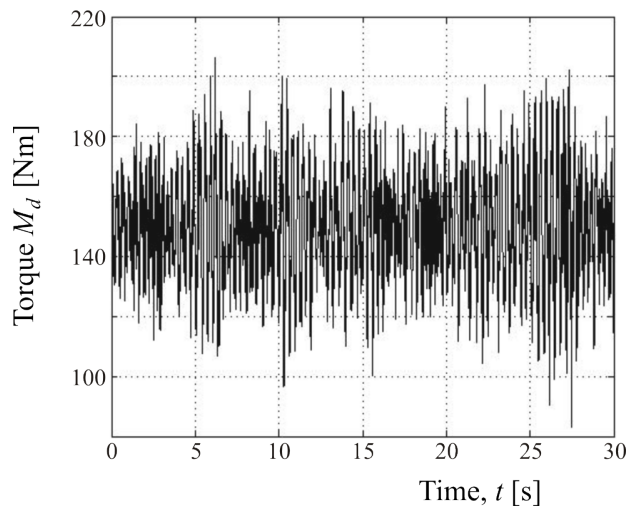

Fig. 12. Changes in torque on the half shaft when drive-wheel passing over Pavement 2

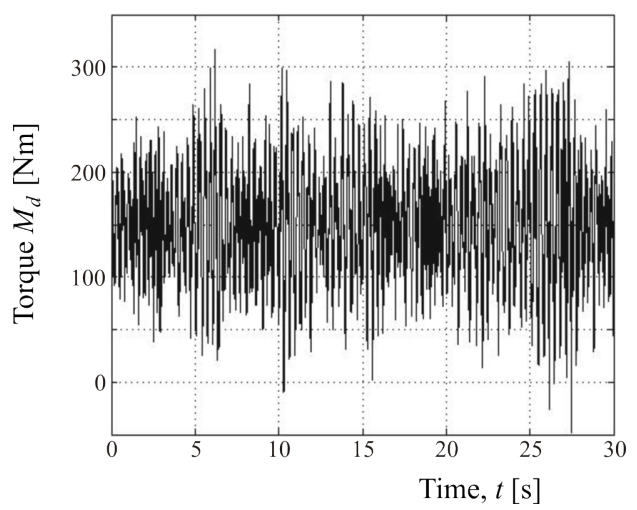

Fig. 14. Changes in torque on the half shaft when drive-wheel passing over Pavement 4

the vehicle half-shaft torsion stress and the histograms of the relative number of occurrences of amplitude load. The case of the stress of the analysis is presented for all the pavements noted in Table 2.

In the Figs. 15 to 22, a significant change in the half-shaft torque can be noticed, depending on the pavement characteristics. 


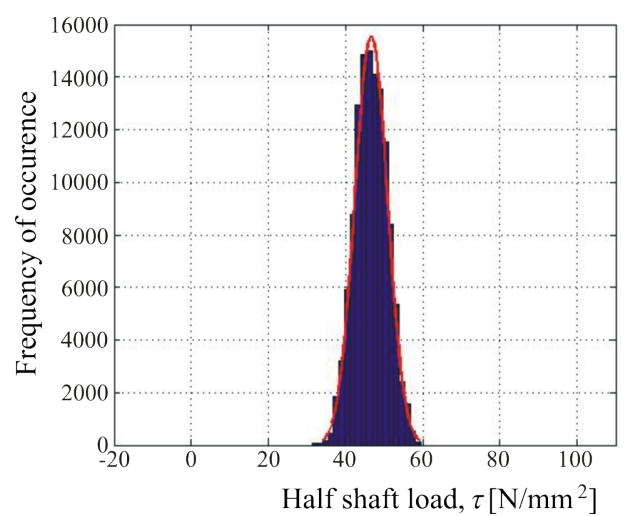

Fig. 15. Histogram of the half-shaft torsion torque stress when drive-wheel passing over Pavement 1

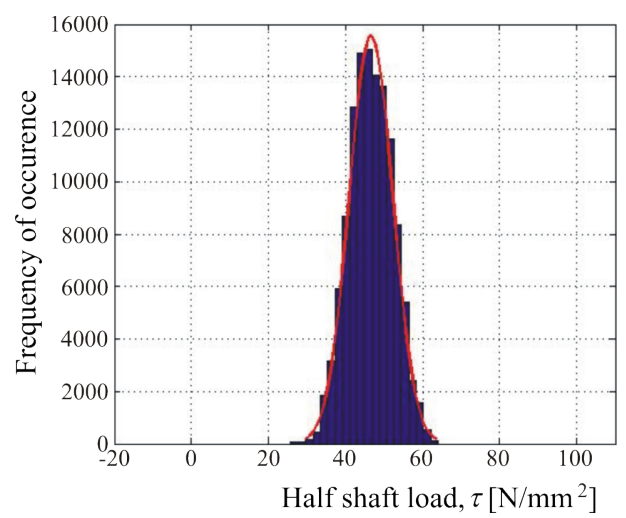

Fig. 17. Histogram of the half-shaft torsion torque stress when drive-wheel passes over Pavement 2

For an analysis of the half-shaft lifespan, a half-shaft material (Č.1530) with the characteristics $\tau_{D(-1)}=180 \mathrm{~N} / \mathrm{mm}^{2}$ and $\tau_{D(0)}=230 \mathrm{~N} / \mathrm{mm}^{2}$ was used as an example. The calculation was done according to the Sorensen-Kogaev method. The following values were used in the calculation: stress $\tau_{\min }=0.6 \times \tau_{D}$, base cycle number $5.6 \times 10^{6}$ and Wöhler curve slope exponent 2.6. The half-shaft diameter is $22.8 \mathrm{~mm}$.

Through the lifespan analysis and according to the load characteristics obtained by the simulated movement of the vehicle drive-wheel across the four types of pavement, the half-shaft lifespans for Pavements 3 and 4 were obtained. In the conditions of differing pavement types, the lifespan reduction amounts to $88 \%$ in comparison with Pavements 3 and 4 . The lifespan values are not calculated for the first two categories of a pavement because the method used for the calculating of a lifespan uses only the stress values exceeding $60 \%$ of $\tau_{D}$.

Based on the results of the analysis, it is clear that the pavement characteristics, in terms of a height of

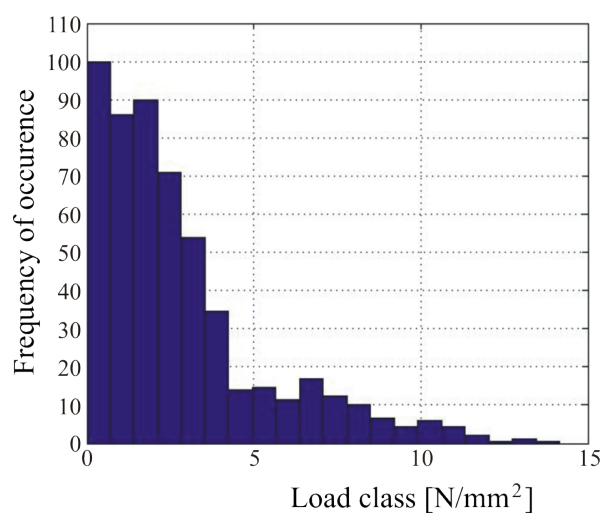

Fig. 16. The relative number of occurrences of the amplitude of the torsion torque of the half shaft when drive-wheel passing over Pavement 1

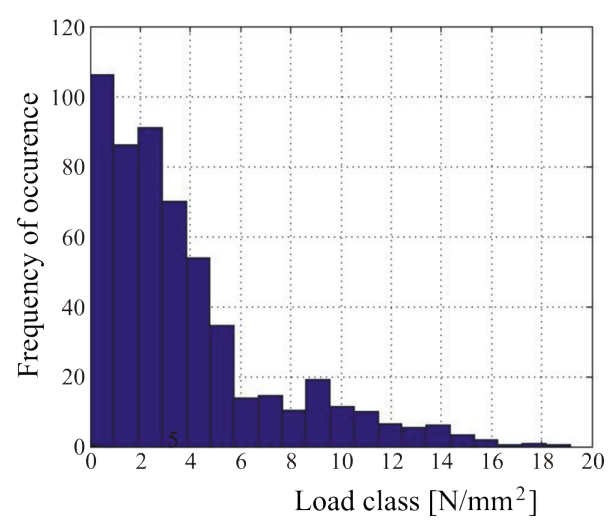

Fig. 18. The relative number of occurrences of the amplitude of the torsion torque of the half shaft when drive-wheel passes over Pavement 2

irregularities, significantly affect a vehicle half-shaft stress and lifespan in a way that the lifespan decreases with increasing pavement irregularities. As for the input data for calculating the half-shaft service life and the calculated service life, they are given only as an example for a general conclusion on the stated influences, and not with the aim of dwelling on a specific half shaft.

\section{CONCLUSIONS}

This paper gives a description of the set mathematical model of the dynamic behaviour of a drive and support system in a vehicle, thus enabling the execution of the analysis of the lifespan of the vehicle drive system elements. In addition to the mathematical model, this paper presents the conducted analysis of the impact of surface irregularities on the load of a vehicle drivewheel half shaft, with a given example of the analysis of lifespan of the half shaft as a part of the drive system. 


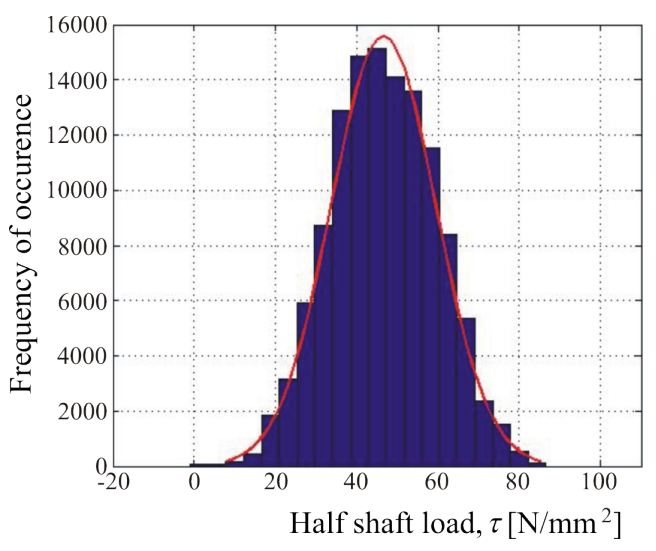

Fig. 19. Histogram of the half-shaft torsion torque stress when drive-wheel passes over Pavement 3

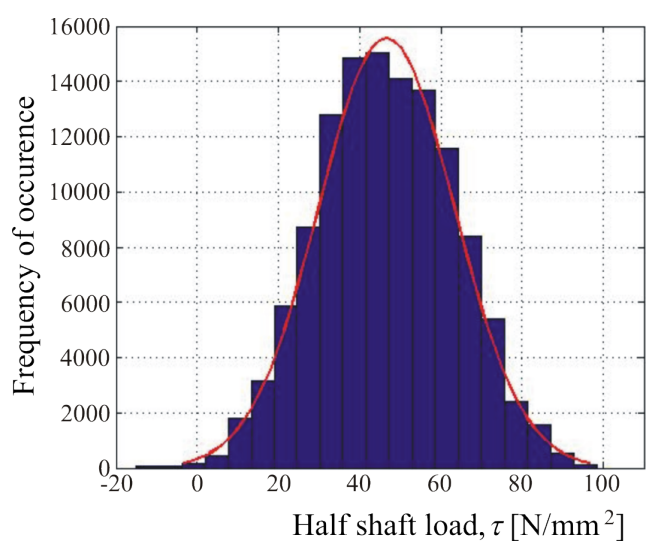

Fig. 21. Histogram of the half-shaft torsion torque stress when drive-wheel passes over Pavement 4

Based on the above content, it is possible to formulate the following conclusions:

- when the wheel passes over pavement with irregularities, forces of an extremely dynamic character are generated, with directions different from those in a vehicle moving on a flat pavement,

- the pavement surface irregularities have a significant effect on the interaction of the wheel with the road,

- the forces generated at the contact point between the wheel and the pavement depend on the characteristics of pavement irregularities.

The results and conclusions concerning the impact of pavement irregularities on the load and a lifespan of the vehicle half shaft require the choice of parameters of a vehicle systems not only in terms of their impact on driving comfort, handling and stability, but also, from the standpoint of impact on load and the lifespan of the drive train elements. This

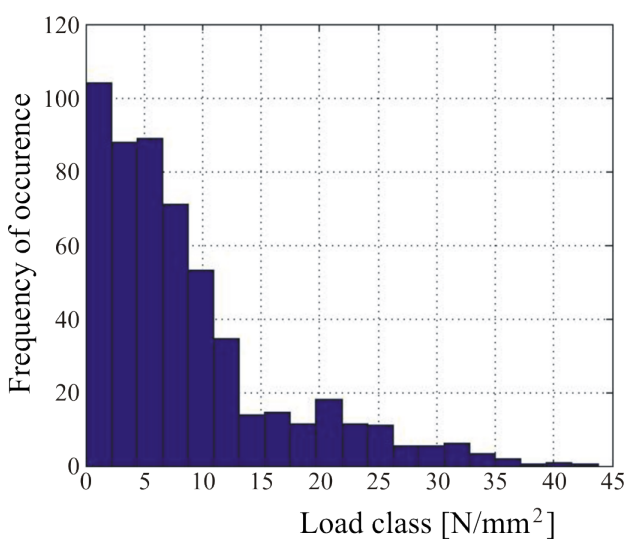

Fig. 20. The relative number of occurrences of the amplitude of the torsion torque of the half shaft when drive-wheel passes over Pavement 3

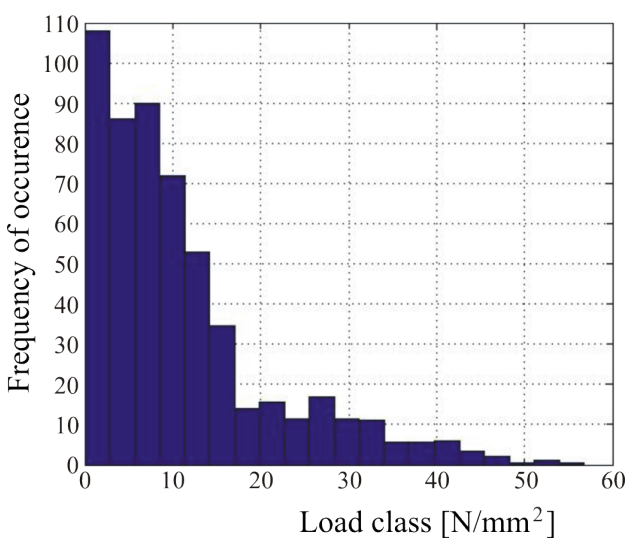

Fig. 22. The relative number of occurrences of the amplitude of the torsion torque of the half shaft when drive-wheel passes over Pavement 4

is especially vital for the designs of special vehicles spending their service life primarily on roads with bad characteristics, and this would further enhance the process of the development of design and control for such systems.

Based on the experiments and the simulation described in this paper, it can be concluded that the characteristics of a wheel force and a change of a suspension position are very complex in cases in which a vehicle moves along an uneven road surface. The presented model has an advantage of a simple adjustment of a vehicle configuration to different vehicle types and to the different configurations of their systems.

\section{REFERENCES}

[1] Blundell, M., Harty, D. (2004). The Multibody Systems Approach to Vehicle Dynamics. Elsevier ButterworthHeinemann, Oxford 
[2] Genta, G. (1997). Motor Vehicle Dynamics - Modeling and Simulation. World Scientific Publishing, Singapore, DOI:10.1142/9789812819765_fmatter.

[3] Gillespie, T.D. (1992). Fundamentals of Vehicle Dynamics, SAE, Warrendale, D0I:10.4271/R-114.

[4] Kiencke, U., Nielsen, L. (2000). Automotive Control Systems For Engine, Driveline And Vehicle. SAE, Springer-Verlag Berlin, Heidelberg, New York

[5] Kulakowski, B.T. (ed.) (1994). Vehicle-Road Interaction. ASTM, Philadelphia, D0I:10.1520/stp1225-eb.

[6] Beleckii, A.V. (2008). Modelling of Profile of Road Basement in Tasks of Analysis of Dynamic of Powertrain of Wheeled Machines. Civil Engineering, Road Machines and Technic, Facilities for Civil Engineering. from http://sdm.str-t.ru/ publics/page_6/ accessed on 2014-12-01. (in Russian)

[7] Ahlawat, R., Jiang, S., Mendoza, D., Smith, H.M. (2012). On emulating engine and vehicle transient loads for transmissionin-the-loop experiments. Mechatronics, vol. 22, no. 7, 989996, D0I:10.1016/j.mechatronics.2012.07.001.

[8] Caruntu, C.F., Lazar, M., Gielen, R.H., van den Bosch, P.P.J. (2013). Lyapunov based predictive control of vehicle drivetrains over CAN. Control Engineering Practice, vol. 21 no. 12, p. 1884-1898, D0l:10.1016/j.conengprac.2012.05.012.

[9] Wallenowitz, H. (2006). Automotive Engineering II - Tire Technology - Simulation und Testing. Automotive Institute, Aachen.

[10] Dixon, J. (1996). Tires, Suspension and Handling, $2^{\text {nd }}$ edition, SAE, London, DOI:10.4271/R-168.

[11] Lajqi, S., Pehan, S. (2012). Designs and optimizations of active and semi-active non-linear suspension systems for a terrain vehicle. Strojniški vestnik - Journal of Mechanical Engineering, vol. 58, no. 12, p. 732-743, D0l:10.5545/sv-jme.2012.776.

[12] Popović, V., Vasić, B., Petrović, M., Mitić, S. (2011). System approach to vehicle suspension system control in CAE environment. Strojniški vestnik - Journal of Mechanical Engineering, vol. 57, no. 2, p. 100-109, D0l:10.5545/svjme.2009.018.

[13] Pacejka, H.B. (2006). Tyre and Vehicle Dynamics, $2^{\text {nd }}$ edition. Butterworth-Heinemann, Elsevier, Oxford.

[14] Cebon, D. (1993). Interaction between heavy vehicles and roads. SAE Technical Paper 930001, D0l:10.4271/930001.

[15] Cole, D.J., Cebon, D. (1996). Truck tyres, suspension design and road damage. Proceedings of the International Rubber Conference, Manchester.

[16] Abdullah, S., Choi, J.C. (2006). Using fatigue data editing approach for analysis cycle sequence effects in variable amplitude road loadings. Journal - The Institution of Engineers, vol. 67 , no. 2, p. $47-54$.

[17] Sakai, E., Tominaga, H., Kato, Y., Yamamoto, N., Matsuki, H. (2005). Development of technique for estimating suspension input force during endurance run on rough road. Mitsubishi motors - Technical review, No. 17, p. 45-48, JSAE Paper Number: 20050500.

[18] Huhtala, M., Halonen, P., Sikiö, J. (1998). Measurements on dynamic effects of dual and wide base single tyres. COST-
344 Report, Technical Research Centre of Finland, VTTYhdyskuntatekniika, Espoo.

[19] Sener, A.S. (2012). Determination of vehicle components fatigue life based on FEA method and experimental analysis. International Journal of Electronics, Mechanical and Mechatronics Engineering, vol. 2, no. 1, p. 133-145.

[20] Strelkov, M.N. (2007). Estimational investigation of low frequency correlatively connected oscillations of powertrain and suspension of light duty vehicle. Herald IžGTU, no. 2. (in Russian)

[21] Lee, S.-H.; Lee, J.-H., Lee; Goo, S.-H.; Cho, Y.-C.; Cho, H.-Y. (2009). An evaluation of relative damage to the powertrain system in tracked vehicles. Sensors, vol. 9, no. 3, 1845-1859, DOI:10.3390/s90301845.

[22] Pesterev, A.V., Bergman, L.A., Tan, C.A. (2002). Potholeinduced contact forces in a simple vehicle model. Journal of Sound and Vibration, vol. 256, no. 3, p. 565-572, D0l:10.1006/jsvi.2001.4220.

[23] Foulard, S., Rinderknecht, S., Ichchou, M., Perret-Liaudet, J. (2015). Automotive drivetrain model for transmission damage prediction. Mechatronics, vol. 30, p. 27-54, D0l:10.1016/j. mechatronics.2015.06.008.

[24] Foulard, S., Ichchou, M., Rinderknecht, S., Perret-Liaudet, J. (2015). Online and real-time monitoring system for remaining service life estimation of automotive transmissions Application to a manual transmission. Mechatronics, vol. 30, p. 140-157, D0I:10.1016/j.mechatronics.2015.06.013.

[25] Willmerding, G., Häckh, J., Berthold, A. (2000). Driving cycle, load and fatigue life predictions based on measured route data. Society of Automotive Engineers, paper 01ATT120.

[26] Seherr-Thoss, H. C., Schmelz, F., Aucktor, E. (2006). Universal Joints and Driveshafts, Analysis, Design, Applications. $2^{\text {nd }}$ ed. Springer-Verlag, Berlin, Heidelberg.

[27] Lechner, G., Naunheimer, H. (1999). Automotive Transmissions - Fundamentals, Selection, Design and Application. SpringerVerlag Berlin, Heidelberg.

[28] Durković, R. (2015). Power Transmission. University of Montenegro, Faculty of Mechanical Engineering, Podgorica.

[29] Jovanović, J. (2009). Influence of damage hypothesis on reliability evaluation of vehicle transmission elements. $13^{\text {th }}$ International Research/Expert Conference "Trends in the Development of Machinery and Associated Technology", Hammamet.

[30] Hačaturov, A.A., Afanasjev, V.L., Vasiljev, V.S., Goljdin, G.V., Dodonov, B.M., Žigarev, V.P., Koljcov, V.I., Jurik, V.S., Jakovlev, E.I. (1976). Dynamics of System Road-Pneumatic-VehicleOperator. Engineering, Moscow. (in Russian)

[31] Simović, S. (2011). The Influence of the Suspension System on the Loading and Lifetime of the Vehicle Drivetrain. PhD thesis, Faculty of Engineering, Kragujevac. (in Serbian)

[32] Niesłony, A. (2009). Determination of fragments of multiaxial service loading strongly influencing the fatigue of machine components. Mechanical Systems and Signal Processing, vol. 23, no. 8, p. 2712-2121, DOl:10.1016/j.ymssp.2009.05.010. 